\title{
Revisión del concepto de buenas prácticas educativas que integran tecnologías digitales en el nivel superior: enfoques para su detección y documentación
}

\author{
Review of best educational practices concept that integrate digital technologies \\ at the higher education: approaches to detection and documentation \\ Emmanuel Ángel Argenis Mondragón Beltrán \\ Hugo Moreno Reyes
}

\begin{abstract}
RESUMEN
El concepto de buenas prácticas (BBPP) ha permeado indiscriminadamente en la educación dando pie a la existencia de distintas acepciones e interpretaciones sobre su deber ser, así como de las estrategias para su detección. Las buenas prácticas educativas (BBPPEE) son promovidas para referir un conjunto de acciones o principios que gozan de reconocimiento por los resultados positivos que se pueden obtener de su replicación. En el nivel superior se presentan con frecuencia asociadas a la integración de tecnologías digitales, resaltando el valor de estas para lograr tal reconocimiento. Para contribuir a esclarecer la significación de las BBPPEE en el contexto referido se ha elaborado una revisión exploratoria descriptiva sobre 32 textos publicados en los últimos diez años, obtenidos de un proceso de filtrado en el cual se aplicaron cinco criterios de selección a un corpus de más de 80 documentos científicos. El análisis de contenido se realizó aplicando la codificación temática utilizando como apoyo la matriz bibliográfica. Los resultados permiten deducir que nos situamos en un terreno polisémico e inconcluso, al tiempo que se aportan elementos teóricos sobre sus tipologías, estrategias de detección y recopilación, entre otros elementos que contribuyen al desarrollo conceptual.
\end{abstract}

Palabras clave: buenas prácticas educativas; tecnologías digitales; revisión descriptiva.

\begin{abstract}
The concept of good practices has indiscriminately permeated in education, giving rise to the existence of different meanings and interpretations of its duty to be, as well as the strategies for its detection. Good educational practices are promoted to refer to a set of actions or principles that are recognized for the positive results that can be obtained from their replication. At a higher level, they are frequently associated with the integration of digital technologies, highlighting their value to achieve such recognition. To help clarify the significance of good educational practices in the aforementioned context, a descriptive exploratory review has been prepared on 32 texts published in the last ten years, obtained from a filtering process where five selection criteria were applied to a corpus of more than 80 scientific documents. The content analysis was carried out applying thematic coding using the bibliographic matrix as support. The results allow us to deduce that we are in a polysemic and unfinished ground while providing theoretical elements about their typologies, detection, and collection strategies, among other elements that contribute to conceptual development.
\end{abstract}

Keywords: best educational practices; digital technology; review article. 


\section{INTRODUCCIÓN}

La educación afronta retos importantes y complejos en un escenario digital que pareciera ofrecer un campo fértil de posibilidades para innovar y superarlos. No obstante, estas posibilidades se ven lejanas para muchos actores del proceso educativo que carecen de los conocimientos necesarios sobre el potencial de las tecnologías digitales para mejorar la educación y por lo tanto se ven imposibilitados para aprovecharlas en favor de su praxis. Es por lo tanto necesaria la movilización y gestión de dichos conocimientos, en favor del desarrollo de la inteligencia colectiva que plantea Pierre Lévy (2004) para el "enriquecimiento mutuo de las personas" (p. 19). La sistematización de las BBPP es una solución que desde hace décadas se ha planteado en diversos ámbitos, ya que a decir de Jeri (2008), cada buena práctica es una experiencia innovadora para resolver problemas ya que tiene una base cognitiva vinculada a la acción que se puede encapsular para trasladar el conocimiento tácito a explícito (p. 31). Para comprender de mejor manera el potencial de las BBPP para lograr este propósito es fundamental el estudio y actualización sobre la evolución de conceptualización y las estrategias para detectarlas y recopilarlas.

No existe una definición universal para el concepto de buenas prácticas (BBPP). En general en el contexto educativo se utiliza para emitir una valoración subjetiva sobre aquellos casos exitosos en los cuales su implementación haya acreditado cierto nivel de efectividad en el logro de los resultados, particularmente los de aprendizaje. El propósito de distinguir las buenas prácticas educativas (BBPPEE) es otorgarles visibilidad y con ello atraer la atención de nuevos actores interesados en replicarlas para extender sus beneficios en nuevos contextos.

En consecuencia, en torno a las BBPPEE se ha desarrollado la idea de que es posible aprenderlas y transferirlas, ante ello, las instituciones educativas han destinado

Emmanuel Ángel Argenis Mondragón Beltrán. Profesor de la Facultad de Telemática y Director General de Integración de las Tecnologías de Información de la Universidad de Colima, México. Es maestro en computación por la misma universidad y doctorante en Innovación en Tecnología Educativa por la Universidad Autónoma de Querétaro. Tiene más de 15 años de experiencia en el desarrollo de proyectos de tecnología educativa. Es miembro de la Red Temática Mexicana para el Desarrollo e Incorporación de Tecnología Educativa (Red LaTE) y miembro del Comité de Tecnología Educativa de la Asociación Nacional de Universidades e Instituciones de Educación Superior (ANUIES). Correo electrónico: eargenis@ucol.mx. ID: https://orcid. org/ 0000-0001-7348-7516.

Hugo Moreno Reyes. Profesor-investigador del Centro Interdisciplinario de Investigación y Docencia en Educación Técnica, Querétaro, México. Es doctor en Educación, maestro en Comunicación y Tecnologías Educativas, con especialidad en docencia. Tiene los reconocimientos al perfil deseable Prodep y del Sistema Nacional de Investigadores (Nivel 1, al 2019). Es miembro del cuerpo académico Estudios sobre la Formación de Ingenieros. Entre sus publicaciones recientes se encuentra el capítulo de libro "Proceso de modelación algebraica con fundamentos psicopedagógicos en ingeniería: propuesta de desarrollo" (2019) y "Evaluación del aprendizaje en probabilidad y estadística: referentes para la reconversión de la practica educativa” (2019). Correo electrónico: hmoreno@ciidet.edu.mx. ID: https://orcid.org/0000-0002-7284-9754. 
recursos e implementado políticas orientadas a su detección y promoción. El problema con esta situación es que el concepto es polisémico y se utiliza a discreción por la comunidad educativa sin que necesariamente hayan sido sometidas a algún proceso de evaluación o revisión. Así mismo es usual que las BBPPEE se asocien al empleo de tecnologías digitales, es relevante por lo tanto descubrir cuáles son los elementos y atributos que son valorados como aportación de estas para sustentarlas, además, si se considera que el abanderamiento de las BBPPEE puede tener otros propósitos como la legitimación de políticas educativas o la introducción de procesos de gestión del cambio en la institución (González, 2007), es importante también identificar el papel de las tecnologías digitales para la adopción de tales políticas y procesos.

Puesto que el concepto de buenas prácticas está arraigado en la esfera educativa, conviene revisar constantemente la evolución de este, así como los criterios y condiciones bajo los que se aplica. Para contribuir con dicha revisión se ha hecho una investigación tomando como base un corpus de 32 artículos científicos que datan de los últimos diez años. Como resultado se exponen los principales atributos que caracterizan a las BBPPEE sustentadas en las tecnologías digitales como parte central de su planteamiento, así mismo se ha realizado un análisis sobre las diversas estrategias para su detección y recopilación, a fin de ampliar el panorama y profundizar en las técnicas que se utilizan como parte de su promoción. Este trabajo es una investigación documental que explora el concepto de las BBPPEE aportando elementos que permiten valorar la importancia de identificarlas como tales y su relevancia para innovar y mejorar el proceso educativo.

\section{Metodología}

Se realizó una revisión exploratoria descriptiva, señalada por Guirao-Goris, Olmedo y Ferrer (2008, p. 6) como aquella que caracteriza e indaga lo que se conoce sobre un tema, permitiendo la actualización sobre su evolución. Se admitieron textos en español e inglés de motores vinculados a bases de datos científicas: EBSCO, Redalyc, ERIC, Dialnet, CONRICyT y Google Académico. Se seleccionaron los motores de búsqueda referidos puesto que contienen índices de revistas científicas especializadas en temas educativos, tanto en español como en inglés, muchas de ellas de acceso abierto. Se eligieron los idiomas previamente referidos debido a que, en el caso del español, es posible encontrar publicaciones que reflejan con mayor cercanía los criterios adoptados por los actores que pertenecen a los sistemas educativos que rigen en los países hispanohablantes. En el idioma inglés es posible encontrar un volumen amplio de publicaciones que permiten identificar y contrastar los diversos enfoques sobre la conceptualización de las BBPPEE.

La búsqueda bibliográfica se realizó siguiendo los pasos generales propuestos por Guirao-Goris, Olmedo y Ferrer (2008), que consisten en (1) definir objetivos de 
la revisión, (2) realizar la búsqueda bibliográfica, (3) organizar la información y, por último, (4) la redacción del artículo. Así mismo se siguieron las recomendaciones de Cué, Díaz, Díaz y Valdés (2008), así como de Contreras y Ochoa (2010) y Henríquez y Zepeda (2004) sobre los métodos de búsqueda bibliográfica, el análisis y meta-análisis de los documentos, la síntesis y la redacción, aspectos que fortalecen la calidad de la revisión. En primera instancia se consultaron las fuentes documentales y se estableció una estrategia de búsqueda, se aplicaron criterios de selección de documentos y por último se organizó la información en forma sistemática utilizando como soporte la matriz bibliográfica.

Para la selección de fuentes documentales se conformaron los siguientes términos en la cadena de búsqueda: "buenas prácticas educativas" y "tecnología educativa" o “tecnología digital” o "tecnología de información y comunicación” y "educación superior", así mismo en el idioma inglés "best practices in education" o "good practices in education" y "educational technology" o "digital technology" y "higher education". En total los motores de búsqueda arrojaron más de 1,500 resultados, mismos que se examinaron para eliminar duplicidades -ya que varios títulos aparecieron como parte de los resultados en distintos motores de búsqueda-. Posteriormente se aplicaron filtros con base en los siguientes criterios: (1) que la fecha de publicación no fuese mayor a diez años, (2) que el idioma fuese en español o inglés, (3) que las referencias a las BBPPEE estuvieran situadas preferentemente en el nivel de educación superior, (4) que el artículo o recurso de información versara sobre la presentación o análisis de BBPPEE cuya implementación estuviese sustentada en las tecnologías digitales -también asociadas como tecnologías de información y comunicación-, o bien que el artículo o fuente de información abordara la fundamentación teórica del concepto de buenas prácticas, o bien sobre las estrategias para su detección en el contexto educativo.

Del proceso de selección resultaron 28 documentos, cabe mencionar que solo 21 se sitúan en el nivel superior y los siete restantes no precisan un nivel educativo específico, por lo que al aplicar el criterio de "nivel" no se discriminaron; no así el caso de cuatro trabajos situados en el nivel básico (Caldeiro-Pedreira, Yot-Domínguez y Castro-Zubizarreta, 2018; Borges, Rodríguez-Naveiras y Domínguez, 2016; Fernández, 2016; FONDEP, 2014), que se rescataron por su relevancia, ya que los conceptos que presentan contribuyen a la fundamentación de las BBPPEE. La tabla 1 muestra el flujo de los cambios en los textos admitidos según la aplicación de los criterios de selección.

En total la muestra se conformó de los 32 documentos (18 artículos, cinco libros, seis guías, dos tesis y un reporte) que se enlistan en la tabla 2. 
Tabla 1. Flujo de textos admitidos.

\begin{tabular}{ccc} 
Criterio & Descripción & $\begin{array}{c}\text { Corpus } \\
\text { resultante }\end{array}$ \\
\hline Fecha de publicación & No mayor a diez años & 80 \\
\hline Idioma & Español o inglés & 73 \\
\hline Abordaje de BBPPEE & Presentan BBPPEE o se teoriza sobre su conceptualización & 60 \\
\hline Nivel & Trabajos situados preferentemente en la educación superior & 28 \\
\hline Relevancia & $\begin{array}{c}\text { Se añadieron cuatro trabajos de nivel básico por su } \\
\text { aportación a la fundamentación del concepto de BBPPEE }\end{array}$ & 32 \\
\hline & Fuente: Construcción personal. &
\end{tabular}

Tabla 2. Referencias a los textos admitidos por año de publicación.

\begin{tabular}{|c|c|c|}
\hline Año & Autores & Soporte documental \\
\hline 2019 & $\begin{array}{l}\text { 1. Pérez y Akombo [Holanda] } \\
\text { 2. Blanco, Lacleta y García-Peñalvo [España] } \\
\text { 3. Singh y Saroha [India] } \\
\text { 4. Sorter [EEUU] }\end{array}$ & $\begin{array}{c}2 \text { libros } \\
2 \text { artículos }\end{array}$ \\
\hline 2018 & $\begin{array}{l}\text { 5. Caldeiro-Pedreira, Yot-Domínguez y Castro-Zubizarreta [España] } \\
\text { 6. Guzmán [México] } \\
\text { 7. Tobón, Martínez, Valdez y Quiroz [México] }\end{array}$ & 3 artículos \\
\hline 2017 & $\begin{array}{l}\text { 8. Pacansky-Brock [EEUU] } \\
\text { 9. Ministerio de Educación de Ecuador } \\
\text { 10. Universitat de València [España] } \\
\text { 11. Wilczynski, Cook y Malcom [EEUU] }\end{array}$ & $\begin{array}{l}1 \text { libro } \\
1 \text { artículo } \\
2 \text { guías }\end{array}$ \\
\hline 2016 & $\begin{array}{l}\text { 12. Acuña, Rendón y Sandoval [Costa Rica] } \\
\text { 13. Borges, Rodríguez-Naveiras, Díaz, Domínguez et al [España] } \\
\text { 14. Durán y Estay-Niculcar [España] } \\
\text { 15. Fernández [España] } \\
\text { 16. Flores, Díaz y Rigo [México] } \\
\text { 17. Antisdel [EEUU] } \\
\text { 18. OEI-IBERTic [España] } \\
\text { 19. Power y Kannara [Inglaterra] } \\
\text { 20. Ruiz-Bolívar y Dávila [Venezuela] } \\
\text { 21. Gradaille y Caballo [España] }\end{array}$ & $\begin{array}{l}1 \text { libro } \\
1 \text { tesis } \\
1 \text { guías } \\
7 \text { artículos }\end{array}$ \\
\hline 2015 & $\begin{array}{l}\text { 22. OIT [Ecuador] } \\
\text { 23. Gañán y Rozo [Colombia] } \\
\text { 24. Keppell, Suddaby y Hard [Australia] } \\
\text { 25. Padilla, Moreno y Hernández [México] } \\
\text { 26. Durán, Estay-Niculcar y Álvarez [España] } \\
\text { 27. Hernández, Borges, Valadez y Zambrano [Colombia] } \\
\text { 28. Otto, Evins, Boyer-Pennington y Brinthaupt [EEUU] }\end{array}$ & $\begin{array}{l}1 \text { guía } \\
1 \text { tesis } \\
5 \text { artículos }\end{array}$ \\
\hline 2014 & 29. FONDEP [España] & 1 guía \\
\hline 2012 & $\begin{array}{l}\text { 30. Cámara [México] } \\
\text { 31. Agencia Andaluza de Evaluación Educativa [España] }\end{array}$ & $\begin{array}{l}1 \text { guía } \\
1 \text { libro }\end{array}$ \\
\hline 2010 & 32. Claro [Chile] & 1 reporte \\
\hline
\end{tabular}

Fuente: Construcción personal. 
Como procedimiento para la organización de la información, al ser el objetivo de carácter de revisión, "no existe una estructura preestablecida por lo que es necesario diseñar un guión o una estructura lógica, razonable y secuencial" (Guirao-Goris, Olmedo y Ferrer, 2008, p. 15). Por ello se adaptó la técnica de codificación temática estableciendo las siguientes categorías previas al análisis que se presentan en la tabla 3.

Tabla 3. Categorías de análisis.

\begin{tabular}{cr} 
Categoría & Pregunta asociada \\
\hline Concepto & ¿Cómo se ha definido el concepto de BBPPEE? \\
\hline Atributos & ¿Cuáles atributos caracterizan a una BBPPEE? \\
\hline Estrategias de detección & ¿Cuáles estrategias se utilizan para detectar BBPPEE? \\
\hline Documentación & ¿Qué información se requiere para la documentación de la BBPPEE? \\
\hline & Fuente: Construcción personal.
\end{tabular}

Se utilizó como soporte la matriz bibliográfica en una hoja de cálculo en Excel en donde las categorías corresponden a las columnas y los registros al inventario de 32 de los textos seleccionados. Como evidencia se puede apreciar una muestra de la referida matriz en la figura 1.

\begin{tabular}{|c|c|c|c|c|c|c|c|c|c|}
\hline & A. & B & c & D & E & F & G & H & 1 \\
\hline 1 & Afio & Fuente & Deseripeión & Concepto & Atributos & Documentación & Mátodo Detecelón & $\begin{array}{l}\text { Aportación do las } \\
\text { teenologitas digitaies }\end{array}$ & Tipologla BPE \\
\hline 2 & 2019 & $\begin{array}{l}\text { Blanco, A. F., Lacleta, } \\
\text { M. L. S., s Garcia- } \\
\text { pentalvo, F. J. (2019). } \\
\text { Metodo para disenar }\end{array}$ & $\begin{array}{l}\text { Documento que aporta sobre } \\
\text { atributos y caracteristicas de } \\
\text { las BPE. Gran parte de las } \\
\text { universidades e instituciones }\end{array}$ & $\begin{array}{l}\text { Aunique no } \\
\text { menciona } \\
\text { literalmente el } \\
\text { conceoto de una }\end{array}$ & $\begin{array}{l}\text { innovación, } \\
\text { eficacia, } \\
\text { eficiencla. }\end{array}$ & No & $\begin{array}{l}\text { Convocatoria, } \\
\text { revistas clentificas }\end{array}$ & Innovacion educativa & $\begin{array}{l}\text { Marco, modelo de } \\
\text { proceso o método de } \\
\text { actuación }\end{array}$ \\
\hline 3 & 2019 & $\begin{array}{l}\text { Singh. R, y Saroha, D. } \\
\text { (2019). Role of } \\
\text { Innovations in Teaching- }\end{array}$ & $\begin{array}{l}\text { Plantea el reto continuo para } \\
\text { las universidades de seguir el } \\
\text { paso a los cambios } \\
\text { tecnologicos y com las }\end{array}$ & comberu ve uela & $\begin{array}{l}\text { Efectivas } \\
\text { Sostenibies }\end{array}$ & No & $\begin{array}{l}\text { Deducido: Eventos } \\
\text { académicos, toda } \\
\text { vez que menciona }\end{array}$ & $\begin{array}{l}\text { Cambios en los modelos de } \\
\text { enseñanza y aprendizaje }\end{array}$ & $\begin{array}{l}\text { Marco, modelo de } \\
\text { proceso o método de } \\
\text { actuación }\end{array}$ \\
\hline 4 & 2019 & $\begin{array}{l}\text { Sorter, H. (2019). Best } \\
\text { Practices af Learning } \\
\text { Analytics. } \\
\text { Implementations in }\end{array}$ & $\begin{array}{l}\text { Compendio de articulos que } \\
\text { describen experiencias y } \\
\text { recomendaciones para la } \\
\text { implementacion de LA }\end{array}$ & No & No & No & varas en un paper & $\begin{array}{l}\text { Estudio del aptencizaje del } \\
\text { estudiante }\end{array}$ & $\begin{array}{l}\text { Modelo de actividad } \\
\text { concreta }\end{array}$ \\
\hline 5 & 2018 & $\begin{array}{l}\text { Caldeiro-Pedreira, M.- } \\
\text { C., Yot-Dominguez, C., } \\
\text { \& Castro-Zubizarreta, A. } \\
\text { (2018). Detección de }\end{array}$ & $\begin{array}{l}\text { Observación de buenas } \\
\text { practicas en uso de } \\
\text { dispositivos móviles. Fincado } \\
\text { en UNESCO MOST }\end{array}$ & $\begin{array}{l}\text { Es una iniciativa, } \\
\text { una politica o un } \\
\text { modelo de } \\
\text { actuación exitoso }\end{array}$ & $\begin{array}{l}\text { Innovadora } \\
\text { Efectiva } \\
\text { Sostenible } \\
\text { Replicabie }\end{array}$ & No & Anâlisis documental & $\begin{array}{c}\text { Mejora del rendimiento } \\
\text { academico y motivacional de } \\
\text { los estudiantes }\end{array}$ & $\begin{array}{l}\text { Modelo de actividad } \\
\text { concreta }\end{array}$ \\
\hline 6 & 2018 & $\begin{array}{l}\text { Guzmen, J, C. (2018). } \\
\text { Best teaching practices } \\
\text { of university professors. } \\
\text { Revista lberoamencana }\end{array}$ & $\begin{array}{l}\text { El articulo está centrado en el } \\
\text { analisis de las conductas } \\
\text { docentes en función de } 40 \\
\text { profesores que fueron }\end{array}$ & $\begin{array}{l}\text { Conjunto de } \\
\text { acciones que } \\
\text { realizan los } \\
\text { docentes para }\end{array}$ & $\begin{array}{l}\text { - Centradas en } \\
\text { el aprendizaje } \\
\text { del estudiante } \\
\text { - Buenas }\end{array}$ & No & No & $\begin{array}{c}\text { Transformación del rol del } \\
\text { docente }\end{array}$ & $\begin{array}{l}\text { Modelo de actitudes y } \\
\text { aptitudes docentes o } \\
\text { principios de actuación }\end{array}$ \\
\hline 7 & 2018 & $\begin{array}{l}\text { Tobon, S., Martinez, J., } \\
\text { Valdez R., E., y Quiriz, } \\
\text { T. (2018). Practicas } \\
\text { pedaabaicas: Anatisis }\end{array}$ & $\begin{array}{l}\text { Se centra en desarrollo de } \\
\text { prácticas pedagógicas, } \\
\text { presenta una nueva } \\
\text { perspectiva centrada en las }\end{array}$ & $\begin{array}{l}\text { Tracicionalmente } \\
\text { las prácticas } \\
\text { pedagogicas so } \\
\text { caracterizan por }\end{array}$ & $\begin{array}{l}\text { - Mejora de las } \\
\text { condiciones de } \\
\text { vida } \\
\text { - Colaboración }\end{array}$ & $\begin{array}{l}\text { En la } \\
\text { socioformación se } \\
\text { proponen las } \\
\text { siquientes }\end{array}$ & No & $\begin{array}{l}\text { Transformación del fol del } \\
\text { docente }\end{array}$ & $\begin{array}{l}\text { Modelo de actitudes y } \\
\text { aptitudes docentes o } \\
\text { principios de actuación }\end{array}$ \\
\hline a & 2017 & $\begin{array}{l}\text { Educación, M. de. } \\
\text { Buenas Prácticas } \\
\text { Educativas Exitosas y/o } \\
\text { Innovadoras. . (2017). }\end{array}$ & $\begin{array}{l}\text { Estándar para documentar } \\
\text { buenas prácticas educativas } \\
\text { exitosas y/o innovadoras. } \\
\text { Presenta Ficha documental. }\end{array}$ & $\begin{array}{l}\text { Practicas } \\
\text { educativas } \\
\text { enfocadas en el } \\
\text { loaro de }\end{array}$ & $\begin{array}{l}\text { Pertinentes } \\
\text { Sostenibles } \\
\text { Replicables } \\
\text { Verificables }\end{array}$ & $\begin{array}{l}\text { Fecha } \\
\text { Apoyos de la } \\
\text { práctica } \\
\text { Contexto }\end{array}$ & $\begin{array}{l}\text { Convocatoria para } \\
\text { publicación en } \\
\text { baletin }\end{array}$ & $\begin{array}{c}\text { Mejora del rendimiento } \\
\text { académico y motivacional de } \\
\text { los estudiantes }\end{array}$ & $\begin{array}{l}\text { Modelo de actividad } \\
\text { concreta }\end{array}$ \\
\hline 9 & 2017 & $\begin{array}{l}\text { UvCatedres. Guia para } \\
\text { participar en los premios } \\
\text { excellentia ex cathedra - } \\
\text { universitat de valència. }\end{array}$ & $\begin{array}{l}\text { Guia para enviar prácticas al } \\
\text { observatorio de BPE de la } \\
\text { universidad. Convocatoria del } \\
\text { observatorio }\end{array}$ & $\begin{array}{l}\text { El conjunto de } \\
\text { principios. } \\
\text { medidas. }\end{array}$ & $\begin{array}{l}\text { Efectividad } \\
\text { Innovacion } \\
\text { Pertinencia } \\
\text { Sostenibilidad }\end{array}$ & No & $\begin{array}{c}\text { Convocatoria a } \\
\text { premio }\end{array}$ & $\begin{array}{l}\text { Mejora de la calidad } \\
\text { educativa }\end{array}$ & $\begin{array}{l}\text { Modelo de actividad } \\
\text { concreta }\end{array}$ \\
\hline 10, & 2017 & $\begin{array}{l}\text { Pacansky-Brock, M. } \\
\text { (2017). Best Practioes } \\
\text { for Teaching with } \\
\text { Emeraing Technoloaies }\end{array}$ & $\begin{array}{l}\text { Es un libro de buenas practicas } \\
\text { para integrar tecnologias en el } \\
\text { aula. Aporta al enforque de } \\
\text { recomendaciones con cierto }\end{array}$ & No & $\begin{array}{l}\text { Electiva } \\
\text { Impacto } \\
\text { positivo }\end{array}$ & $\begin{array}{l}\text { Cada BPE del } \\
\text { libro presenta } \\
\text { minimamente: } \\
\text { Titulo }\end{array}$ & $\begin{array}{c}\text { Convocatorio a } \\
\text { publicación de libro }\end{array}$ & $\begin{array}{l}\text { Romper las barreras de } \\
\text { tiempo y espacio }\end{array}$ & Recomendaciones \\
\hline 11 & 2017 & $\begin{array}{l}\text { Wilczynski, } \mathrm{V} \text {. y Cook, } \\
\text { Malcom (2017). } \\
\text { Identifying and Sharing } \\
\text { Best Practioes in }\end{array}$ & $\begin{array}{l}\text { La buena práctica consiste on } \\
\text { la organización de un } \\
\text { symposium, ISAM donde } \\
\text { diversos actores pueden }\end{array}$ & No & No & No & Evento académico & $\begin{array}{c}\text { Desarrollo de habilidades de } \\
\text { auto-aprendizaje, reatividad } \\
\text { e innovacion }\end{array}$ & $\begin{array}{l}\text { Modelo de actividad } \\
\text { concreta }\end{array}$ \\
\hline 12 & 2016 & $\begin{array}{l}\text { Acuña Sossa, M., Gill } \\
\text { Rendon, M. E., \& } \\
\text { Sandoval Poveda, A. M. } \\
\text { (2016) Buenas. }\end{array}$ & $\begin{array}{l}\text { El articulo describe la } \\
\text { colaboración entre el TEC y la } \\
\text { Universidad Estatal a Distancia } \\
\text { de Costa Rica para seleccionar }\end{array}$ & No & No & No & No & $\begin{array}{l}\text { Colaboración para } \\
\text { intercambiar recursos } \\
\text { educativos }\end{array}$ & Recomendaciones \\
\hline 4 & t. & Matrix bibliogratifica BPE & + & & & & & & \\
\hline
\end{tabular}

Figura 1. Muestra de la matriz bibliográfica de las BBPPEE. 
La hoja de cálculo permite la clasificación, manipulación y asequibilidad de la información que se va generando del análisis, facilitando la contrastación de ideas, de opiniones y postulados de las diversas obras estudiadas. Así mismo los filtros y otras herramientas de organización de información que poseen estas aplicaciones informáticas son de utilidad para determinar frecuencias y sintetizar información, lo que favorece el descubrimiento de tendencias y la discriminación de datos de poca utilidad.

Como parte del proceso de revisión se identificaron los documentos que desarrollan una fundamentación del concepto de BBPP y aquellos en los que no -que corresponden principalmente a los trabajos que han sido escritos para presentarlas-. En este último caso se analizó si era posible hacer deducciones objetivas a partir de los diversos elementos que desarrollan los autores en sus trabajos; mismo caso para los atributos y los métodos de detección. Para el caso de la documentación, los campos de información emergieron de las fichas que se refieren o se presentan en las guías y formatos que se utilizan como parte de las estrategias de detección. Por último se extrajeron los valores que se resaltan en los textos respecto a las aportaciones de las tecnologías digitales para sustentar o posibilitar la implementación de las BBPPEE.

\section{Resultados}

Los 32 textos admitidos abordan el tema de las BBPPEE con diversos propósitos, mismos que han sido clasificados para identificar los enfoques desde los cuales se ha elaborado la revisión que se presenta. Como se aprecia en la figura 2, en lo general, es posible identificar cuatro intencionalidades de los textos revisados: (1) presentar

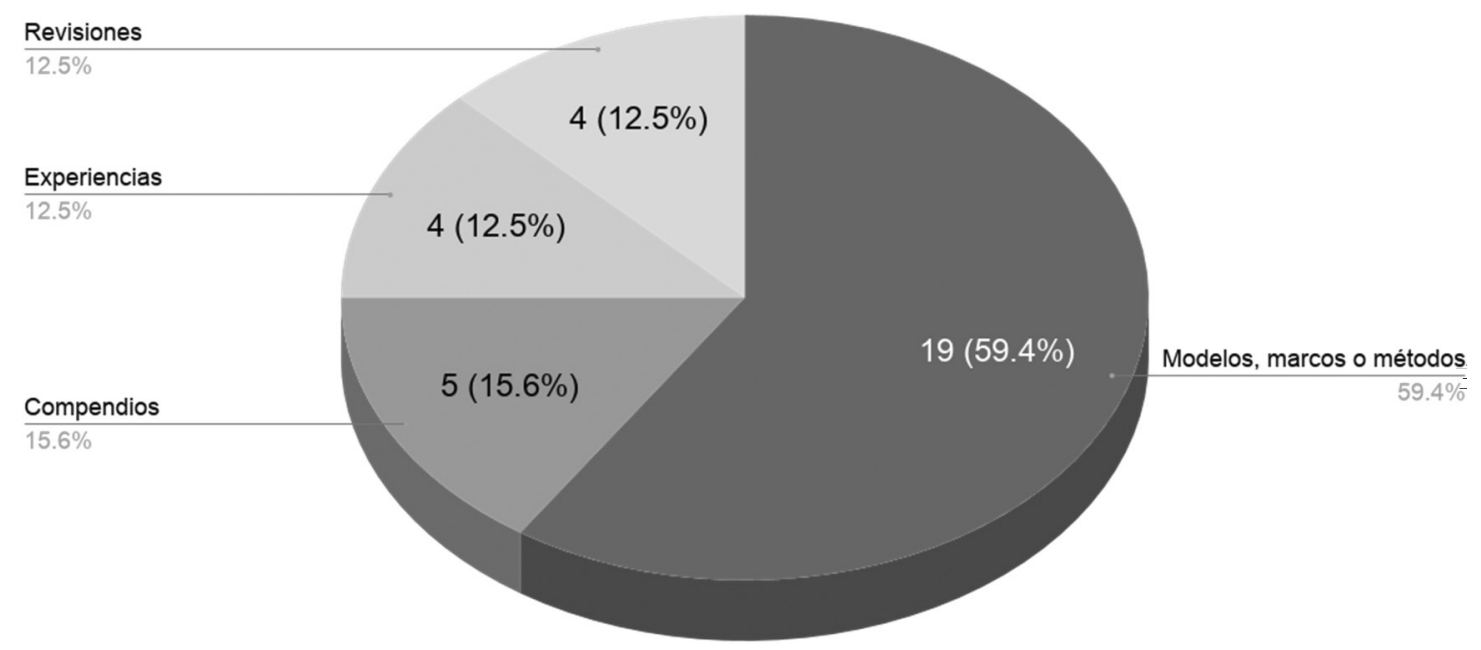

Figura 2. Clasificación de textos según su propósito.

Fuente: Construcción personal. 
compendios de BBPPEE con relación a una temática, (2) presentar los resultados de la experiencia de implementación de una BBPPEE, (3) presentar un marco, modelo o método para la selección de BBPPEE y (4) presentar la revisión o análisis de una BBPPEE.

La mayor cantidad de textos corresponde a propuestas de modelos, marcos o métodos orientados a la selección de BBPPEE, estos marcos al igual que los artículos de revisión han sido de gran utilidad para el desarrollo de la conceptualización que se presenta en este trabajo, así mismo para la identificación de estrategias de detección. El resto de los documentos, que corresponden a la presentación de BBPPEE, ya sea como resultados de una experiencia de implementación o como compendios de estas, han sido de utilidad para identificar la variedad de acepciones e interpretaciones que existen para referirlas.

Como se puede apreciar en la figura 3, la mayor parte de los textos revisados están enfocados en el nivel superior en correspondencia con los criterios de selección que se han expuesto previamente. Sin embargo, como se ha expuesto anteriormente, no todos los trabajos que se admitieron se enfocan en este nivel, algunos están dirigidos al nivel básico y otros realizan un abordaje general de la temática sin distinción del nivel educativo.

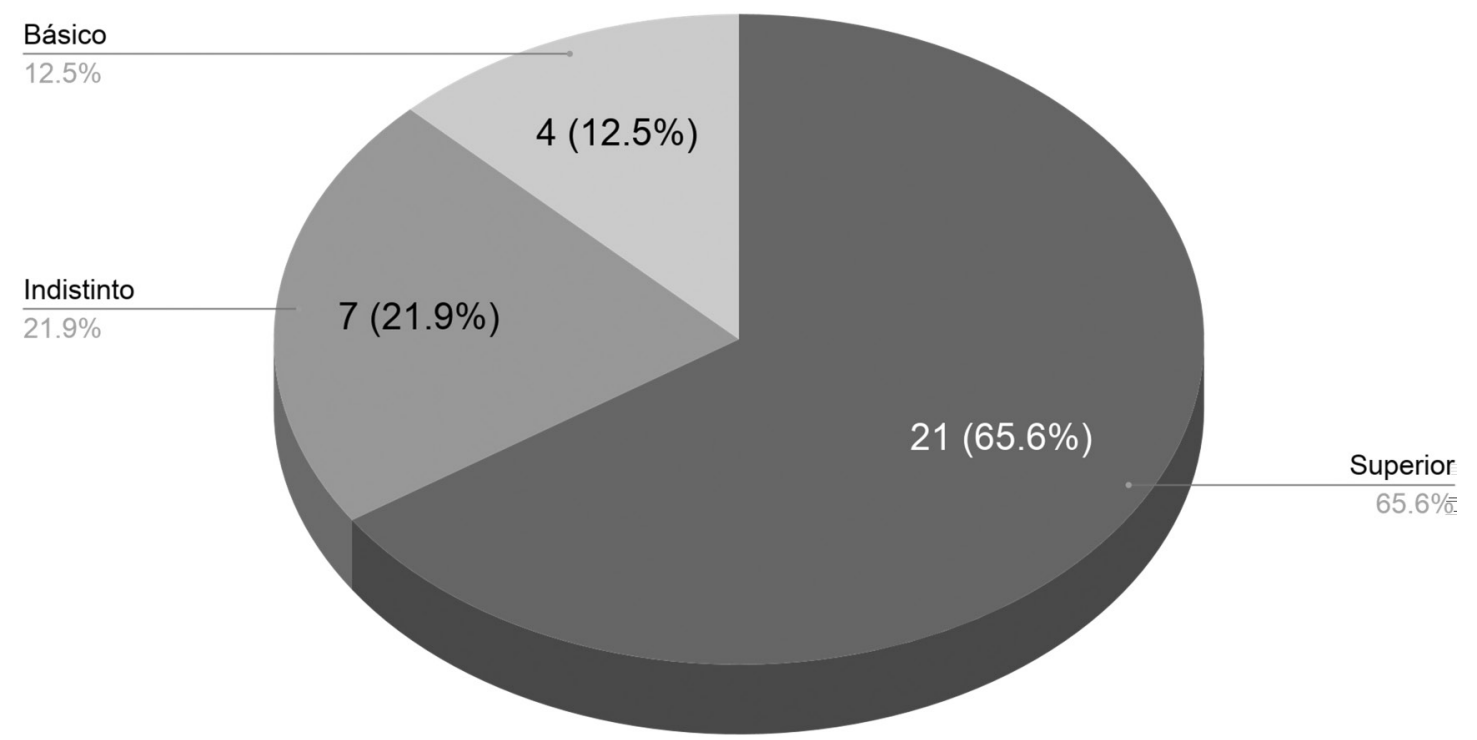

Figura 3. Clasificación de textos según el nivel educativo. Fuente: Construcción personal.

Respecto a las temáticas centrales que se abordan en los textos revisados, la mayor cantidad de estos se enfoca en presentar BBPPEE sustentadas en la integración de las tecnologías digitales en el proceso educativo, seguidas por la innovación educativa, 
la educación en línea o virtual, la transformación del rol del docente, el desarrollo de comunidades de aprendizaje, entre otros, como se puede apreciar en la figura 4. Cabe mencionar que el título de las temáticas que se aprecian en la gráfica atiende a una categorización general elaborada para sintetizar los temas específicos de cada texto.

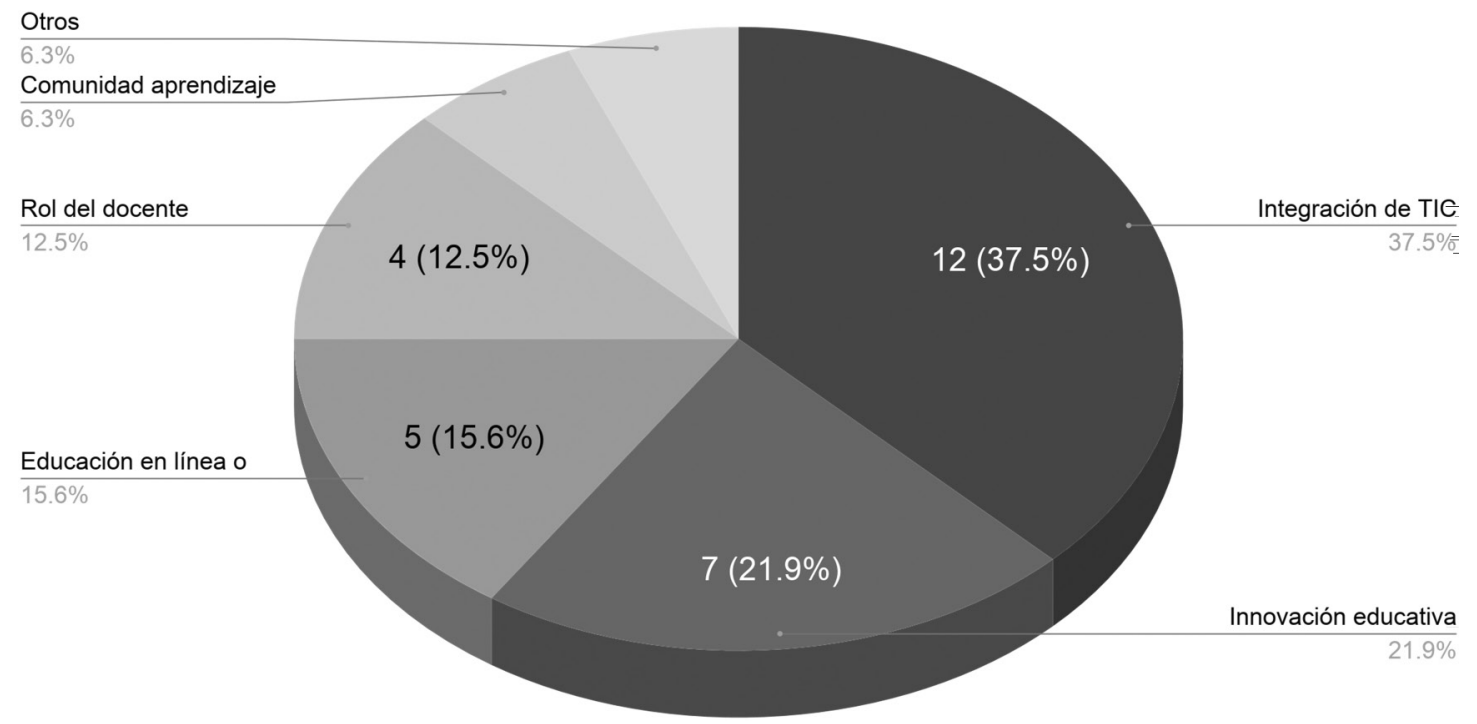

Figura 4. Clasificación de textos según la temática.

Fuente: Construcción personal.

\section{El concepto de buenas prácticas educativas}

El término buenas prácticas educativas (BBPPEE) tiene su origen en el de las buenas prácticas (BBPP), que se utiliza ampliamente en diversos campos del conocimiento y contextos profesionales. De los 32 textos referidos anteriormente (ver tabla 2), solo en 19 se ha desarrollado un marco teórico o conceptual sobre el significado de alguno de los siguientes términos: "buenas prácticas", "mejores prácticas", "good practices", "best practices" -según el idioma en el cual se haya escrito el documento-, como fundamentación del contenido que desarrollan. En los trece documentos restantes -en su mayoría compendios que refieren buenas prácticas-se asume que el lector conoce o está familiarizado con el concepto, o bien que no es necesario desarrollar un marco conceptual puesto que el propósito no es teorizar sino difundir las prácticas concretas. Según Escudero (2009, citado por Gañán y Rozo, 2015), la conceptualización de las BBPP en el contexto educativo es relativamente reciente pero no es novedosa ni desconocida, siempre ha existido la necesidad de mejorar los resultados y las condiciones en las que se desarrolla el proceso educativo, "convirtiendo el concepto en un estandarte que permite construir el deber ser de la educación en la sociedad” (p. 31). 
Respecto al origen del concepto, hay coincidencia en que proviene de otros ámbitos distintos al educativo. La corriente no es propia del discurso pedagógico, sino que se ha adoptado de los modelos empresariales que promueven el desarrollo de la calidad como cultura organizacional y del trabajo. Al respecto se señala que el término proviene de la traducción de best practices, término anglosajón para referir las prácticas exitosas reconocidas por ser innovadoras y replicables en los procesos industriales, del campo de la administración y la gestión pública, no siendo clara la fecha de su origen en el contexto educativo (FONDEP, 2014; AAEE, 2012).

Gañán y Rozo (2015) mencionan que el concepto se ha adoptado gradualmente en el contexto educativo al igual que en otras disciplinas desde finales de la década de los 80, lo que complica su rastreo, sin embargo se observa un incremento en la frecuencia de la aparición del término buena práctica educativa para referir principios de acción y procedimientos innovadores para mejorar la calidad educativa, entre los años 2000 y 2013 (p. 95). No es claro el momento preciso en el que se generó un vínculo del concepto hacia la esfera educativa, sin embargo autores como Durán y EstayNiculcar (2016) se lo atribuyen a Chikering y Gamson (1987), quienes desarrollaron siete principios orientadores de las BBPP en la educación universitaria.

Eventualmente el concepto se diseminó, promovido principalmente por programas de organismos y asociaciones internacionales como la OIT, la UNICEF o la UNESCO, entre otros. Por mencionar un ejemplo, en el programa de gestión de las transformaciones sociales -MOST, por sus siglas en inglés- de la UNESCO se definieron los atributos que deben caracterizar a una buena práctica. Sobre dicha definición diversos autores han fincado la fundamentación de sus trabajos, como Gradaille y Caballo (2016). Así mismo autores como Bralavsky, Abdoulaye y Patiño (2003, citados por AAEE, 2012) han contribuido a la construcción y vinculación del concepto al campo educativo.

En lo general se entiende por BBPPEE a las acciones de intervención que han sido reconocidas por los beneficios que han generado en determinado contexto para transformarlo positivamente y mejorar la calidad educativa, lo que las ha vuelto modelos a imitar por nuevos actores con la intención de obtener los mismos beneficios mediante su replicación en nuevos escenarios.

Sin embargo, como lo menciona Claro (2010), lo relevante de una BPE no es el proceso o procedimiento que se comparte en sí mismo - una interpretación simplista e ilusoria-, sino el reto que conlleva trasladarla a un nuevo contexto, ya que al hacerlo se resuelven nuevas problemáticas - propias del nuevo escenario-, induciendo a la innovación educativa y enriqueciendo la evolución de la BPE.

A través del intercambio y replicación es que las BBPP maduran y eventualmente hay autores que sostienen que se convierten en mejores prácticas. Como se ha mencionado previamente, el término buena práctica se adopta de la traducción 
del anglicismo best practices, cuya traducción literal corresponde en realidad a mejores prácticas, sin embargo, la coincidencia en los acrónimos de ambos términos "BP", ha propiciado que se utilicen cual si fuesen equivalentes, lo que ha contribuido a generar confusión (Cámara, 2012).

En el idioma inglés también se utiliza -aunque menos- el término good practice, cuya traducción literal sí corresponde a la buena práctica, siendo bestpractices el término correcto para mejores prácticas, refiriéndose a aquellas que han prevalecido o destacado sobre las demás por sus mejores resultados, siendo modelos que habitualmente se promueven como estándares a replicar. Existe otro enfoque en el cual las BBPP no son buenas por su efectividad probada sino por su buena intencionalidad, es decir, aquellas que incluso pudiesen nunca haber sido evaluadas pero que por el simple hecho de buscar una mejora de los resultados son consideradas buenas.

La OIT (2015) establece tres niveles de maduración de una práctica para convertirse en buena. La primera etapa es la innovación, en la cual se ha implementado pero no se ha evaluado, se caracteriza por su buena intencionalidad; la siguiente etapa es la práctica exitosa, aquella que ha sido evaluada y se ha acreditado su efectividad; posteriormente la buena práctica replicada, cuya efectividad se ha demostrado en nuevos contextos diferentes al original. Bajo este enfoque, la buena práctica replicada es en cierto sentido parecida a una mejor práctica.

En lo que respecta a las BBPPEE, existen variaciones en las interpretaciones sobre su significatividad, sobre todo si se analiza su materialización en función de los alcances que persiguen. El espectro de lo que puede significar o referirse va desde una simple recomendación -usualmente hecha por un docente o algún profesional experto en el área educativa- hasta un marco o modelo de proceso que puede incluso extenderse más allá de la escuela.

La tabla 4 muestra las tipologías de BBPPEE que se han podido deducir del análisis de la revisión literaria.

\section{Atributos de las buenas prácticas educativas}

Para profundizar en la conceptualización, la tabla 5 muestra un listado de atributos o características que acompañan al concepto de BPE en los textos analizados.

Con base en los resultados, el atributo más relevante que caracteriza a las BBPPEE es la efectividad, en un segundo bloque se ubican la sostenibilidad y la colaboración, seguidas de la pertinencia, transferibilidad e innovación. Sobre este último atributo es relevante hacer énfasis en que toda BPE busca transformar el escenario educativo ya sea aportando nuevos métodos o herramientas o bien haciendo cambios en las estructuras y formas de efectuar los procesos para poder trasladar las prácticas a los nuevos contextos, lo que implica innovar instrumentando nuevos escenarios para lograr una exitosa experiencia de replicación. 
Tabla 4. Principales tipologías asociadas al concepto de BBPPEE.

\begin{tabular}{|c|c|c|}
\hline Tipo & Descripción & $\begin{array}{l}\text { Referentes } \\
\text { (ver autores } \\
\text { en tabla 2) }\end{array}$ \\
\hline $\begin{array}{c}\text { Marco o modelo } \\
\text { de proceso }\end{array}$ & $\begin{array}{l}\text { Bajo este enfoque, las BBPPEE representan un proceso general de intervención } \\
\text { sistematizado que puede extenderse más allá del aula y del proceso enseñanza- } \\
\text { aprendizaje. Busca mejorar la calidad de los resultados a través de la eficientización } \\
\text { y la estandarización de los métodos, las figuras y las relaciones entre los actores que } \\
\text { participan e interactúan a través de la práctica. Es común que las iniciativas reconocidas } \\
\text { bajo esta acepción se impulsen desde la alta dirección de la organización a través } \\
\text { de políticas y programas que buscan transformar la realidad educativa. }\end{array}$ & $\begin{array}{c}1,2,14,15,19, \\
21,22,30,32\end{array}$ \\
\hline $\begin{array}{c}\text { Modelo de } \\
\text { actividad concreta }\end{array}$ & $\begin{array}{l}\text { Las BBPPEE pueden ser procedimientos concretos para intervenir o resolver una } \\
\text { problemática específica. Toman la forma de una receta que sirve como guía para realizar } \\
\text { cierta actividad. Es común que surjan de los docentes, quiénes comparten los resultados } \\
\text { de sus prácticas por diversos medios. Este tipo de prácticas se caracterizan por estar } \\
\text { bien documentadas y compartir los recursos didácticos para su replicación. }\end{array}$ & $4,5,16,29,31$ \\
\hline $\begin{array}{l}\text { Modelo de actitudes } \\
\text { y aptitudes docentes }\end{array}$ & $\begin{array}{l}\text { Esta acepción se refiere a los aspectos de actitud y aptitud que deben orientar la } \\
\text { actividad docente para adoptar un rol que propicie la innovación educativa y el } \\
\text { aprovechamiento de los recursos para transformar el escenario educativo. Bajo este } \\
\text { enfoque se resaltan los valores que caracterizan el modelo del docente del siglo XXI, } \\
\text { por ello, es común que se les nombre buenas prácticas docentes. Se materializan en } \\
\text { guías o principios generales que orientan la actuación del docente para propiciar } \\
\text { escenarios adecuados para favorecer el aprendizaje. }\end{array}$ & $6,7,13,15,20$ \\
\hline Recomendaciones & $\begin{array}{l}\text { Los actores del proceso educativo más experimentados o reconocidos por sus } \\
\text { buenos resultados en el ejercicio de su actividad suelen publicar recomendaciones. } \\
\text { Cuando las BBPPEE toman esta tipología, suelen ser generales y poco sistemáticas, } \\
\text { se limitan a la explicación del uso de herramientas o la realización de actividades } \\
\text { que consideran exitosas derivadas de la experiencia del autor. Bajo esta tipología } \\
\text { las BBPPEE son menos elaboradas y limitadas en su documentación. }\end{array}$ & $8,12,17,28$ \\
\hline
\end{tabular}

Fuente: Construcción personal.

\section{Estrategias para la detección de las buenas prácticas educativas}

No es posible determinar ni asumir que las estrategias que se abordan en esta revisión representan el universo de posibilidades para la detección de las BBPPEE, sin embargo las que aquí se presentan permiten vislumbrar un panorama general de cómo se realiza tal actividad. Se encontraron 21 referencias a cinco estrategias que, en lo general, siguen un proceso que se divide en dos momentos, en el primero, la selección, el organismo o los actores interesados en la detección de BBPPEE establecen ciertos criterios orientadores vinculados a los atributos que caracterizan a una BPE y que han sido descritos previamente (ver tabla 5). Los criterios de selección se aplican siguiendo algún método o guía que se fundamenta en el desarrollo de algún modelo o 
Tabla 5. Atributos relevantes que caracterizan a las BBPPEE según los referentes analizados.

\begin{tabular}{ccc} 
& & Referentes \\
Atributo & Descripción & $\begin{array}{c}\text { (ver autores } \\
\text { en tabla 2) }\end{array}$ \\
\hline Efectiva & Las BBPPEE son efectivas cuando generan un impacto positivo verificable & $2,3,5,6,8,9$, \\
& en el cumplimiento de los objetivos que persiguen. Son eficaces y eficientes & $10,11,14,15$, \\
& para mejorar los resultados de aprendizaje de los estudiantes & $16,17,18,19$, \\
& & $20,21,22,23$, \\
& & $29,30,31,32$ \\
\hline Sostenible & La sostenibilidad es la característica que eventualmente aporta visibilidad a la BPE. & $2,3,5,9,10$, \\
& Significa que ha perdurado, es vigente y soportada por una comunidad & $15,16,18,21$, \\
& y otros factores que la vuelven potencialmente replicable & $22,29,30,31$ \\
\hline Colaborativa & El desarrollo de una BPE es soportado por una comunidad de docentes & $6,7,10,11,12$, \\
& u otros actores quienes a través de un proceso sistematizado colaboran para & $15,16,21,23$, \\
& intercambiar, evaluar y mejorar las mismas en forma continua & $24,29,31,32$ \\
\hline Pertinente & Una BPE debe estar orientada a resolver una problemática educativa real, ya sea que aporte & $6,9,10,14,16$, \\
& una solución nueva o bien que vuelva más eficientes las que ya existen. Dicha solución & $18,21,22,23$, \\
& debe ser coherente y fundamentarse con un sustento pedagógico, tecnológico y ético riguroso. & $29,30,31$ \\
\hline Transferible & Esta característica tiene que ver con la factibilidad y viabilidad de la implementación de la BPE. & $2,5,9,10,14$, \\
& Los recursos materiales y humanos deben apegarse a las condiciones del & $16,21,22,23$, \\
& contexto particular donde se desee replicar o transferir & $29,30,31$ \\
\hline Innovadora & Las BBPPEE están orientadas a la transformación del contexto educativo, su carácter & $5,9,10,11,14$, \\
& innovador se construye a partir del intercambio y replicación a nuevos contextos y realidades. & $16,21,22,29$, \\
& La innovación no se constriñe a la novedad de la práctica en sí misma, sino a las acciones & $30,31,32$
\end{tabular}

Fuente: Construcción personal.

marco orientador en donde usualmente se parte de la definición situada de una BPE y se detallan los métodos para identificarlas y acreditarlas. El segundo momento en la detección de una BPE consiste en la recopilación. Al existir diversas posibilidades para el origen de una BPE, las estrategias para su recopilación también son diversas. Sin embargo, del análisis de la literatura se puede deducir que existen dos enfoques generales, uno pasivo y otro activo.

La existencia de los enfoques referidos está a su vez relacionada con el origen de las BBPPEE. Una posibilidad es que estas emerjan espontáneamente a partir del esfuerzo de uno o varios actores -usualmente docentes-, quienes idean una estrategia para resolver una problemática educativa. Tales prácticas pueden ser identificadas como actividades de cambio que no necesariamente se pueden acreditar de inicio como 
una BPE pero que se pueden orientar a un proceso de refinamiento que las conduzca al perfeccionamiento a través del intercambio (FONDEP, 2014). Bajo esta posibilidad, los actores que intervienen en el diseño e implementación de la práctica no necesariamente están familiarizados con la conceptualización de una BPE, o bien su intencionalidad no está vinculada a la generación formal o estructurada de estas, simplemente buscan mejorar los resultados de aprendizaje y, por lo tanto, estas prácticas suelen tener poca documentación, difusión y visibilidad, lo que complica la detección. En este contexto, la práctica tiene que ser descubierta, se debe entonces establecer una estrategia activa para lograrlo.

La otra posibilidad respecto al origen de las BBPPEE corresponde al esfuerzo deliberado e intencional para diseñarlas por uno o varios profesionales, expertos o bien académicos del campo educativo que buscan transformar su realidad a través de un proceso sistémico y fundamentado. Bajo este enfoque las BBPPEE no emergen de forma espontánea sino que se diseñan y se preparan atendiendo directrices, políticas o principios orientadores que pueden ser promovidos desde organismos externos o bien desde el propio centro o institución donde se desee adoptar la práctica. Usualmente estas BBPPEE toman la figura de proyectos - comúnmente asociados a la innovación educativa- que además se acompañan de estrategias para documentarlas y promoverlas. En este contexto, se espera que las prácticas emerjan para cumplimentar las políticas y directrices establecidas, por tal motivo la organización educativa convoca a su comunidad a que se publiquen y concentren en un espacio común, dando lugar a una recopilación pasiva.

En las estrategias de recopilación pasiva usualmente se emite una convocatoria que tiene asociado algún tipo de estímulo para incentivar a los docentes, practicantes o instituciones a compartir sus BBPPEE en el marco de algún evento académico, concurso o requerimiento de un banco de BBPPEE. Bajo el enfoque activo se implementan programas o estrategias diseñadas para que agentes especializados -llamados por algunos programas cazadores de buenas prácticas- las rastreen o monitoreen en una institución, comunidad o región, apoyándose en las estructuras organizacionales de la institución a través de individuos que fungen como fuentes de información que forman parte de la organización o colaboran con la misma. La tabla 6 muestra algunas de las estrategias de detección mencionadas o deducidas a partir del análisis de la literatura.

\section{Documentación de las buenas prácticas educativas}

La documentación de las BBPPEE es necesaria para recabar las evidencias para acreditarlas. Con base en la documentación será posible evaluarlas y eventualmente publicarlas para que sean reconocidas y susceptibles de ser promovidas para su replicación. Con relación a su publicación, las BBPPEE se pueden encontrar en diversos formatos, siendo el artículo científico, el libro y la ficha documental los principales soportes que 
Tabla 6. Estrategias de detección de BBPPEE.

\begin{tabular}{|c|c|c|c|}
\hline Estrategia & Descripción & Tipo & $\begin{array}{c}\text { Referentes } \\
\text { (ver autores } \\
\text { en tabla 2) }\end{array}$ \\
\hline $\begin{array}{c}\text { Premios } \\
\text { y concursos }\end{array}$ & $\begin{array}{l}\text { Se convoca a la comunidad de practicantes a documentar las BBPPEE en el } \\
\text { marco de algún premio o concurso. Se establecen bases que aplican por igual } \\
\text { a todos los concursantes. Se utilizan formatos diseñados para documentar la } \\
\text { evidencia que permita a un jurado evaluar las BBPPEE y generar un dictamen } \\
\text { de los trabajos más destacados en función del cumplimiento de los requisitos } \\
\text { establecidos. Al ser un concurso, usualmente estas estrategias se enfocan en } \\
\text { los resultados de la práctica y no en el proceso para efectuarla, por lo que la } \\
\text { efectividad, innovación y sostenibilidad suelen ser los criterios más relevantes. }\end{array}$ & Pasivo & $\begin{array}{c}10,21,22, \\
23,29\end{array}$ \\
\hline $\begin{array}{l}\text { Eventos con } \\
\text { publicaciones } \\
\text { académicas }\end{array}$ & $\begin{array}{l}\text { Los eventos académicos pertenecen al escenario científico, en el contexto } \\
\text { educativo se llevan a cabo permanentemente congresos, seminarios, conferencias, } \\
\text { encuentros, entre otros eventos en donde se presentan trabajos académicos con } \\
\text { los resultados obtenidos derivados de alguna investigación o intervención bajo } \\
\text { la bandera de buenas prácticas. Puesto que esta estrategia no está particularmente } \\
\text { diseñada para la detección de BPE, los criterios que los participantes deben } \\
\text { atender son diversos y se apegan al formato que deben seguir las producciones } \\
\text { científicas que se derivarán del evento, por ejemplo, un artículo, un póster, una } \\
\text { presentación, etc. A diferencia del concurso, lo relevante de esta estrategia es el } \\
\text { proceso y los resultados obtenidos que, si bien pueden ser interesantes para los } \\
\text { practicantes, están orientados a una audiencia de expertos y académicos } \\
\text { interesados por el desarrollo científico de la educación. }\end{array}$ & Pasivo & $\begin{array}{l}2,3,4,5 \\
11,21,22\end{array}$ \\
\hline $\begin{array}{l}\text { Observatorios } \\
\text { de BBPPEE }\end{array}$ & $\begin{array}{c}\text { Existen observatorios que se dedican a identificar, analizar, difundir tendencias } \\
\text { y hallazgos sobre BBPPEE. Para ello disponen de una red de colaboración que les } \\
\text { permite indagar en diversos escenarios o espacios de interés. A través de su estructura, } \\
\text { los observatorios generan vínculos con diversas organizaciones educativas y } \\
\text { colaboradores que facilitan la realización de su labor. El observatorio es una } \\
\text { estrategia de recopilación activa porque ejecuta acciones de supervisión } \\
\text { para detectar las BBPPEE. }\end{array}$ & Activo & $21,29,32$ \\
\hline $\begin{array}{c}\text { Programas de } \\
\text { detección } \\
\text { de BBPPEE }\end{array}$ & $\begin{array}{l}\text { Este tipo de programas articulan políticas, recursos materiales y humanos } \\
\text { en forma estratégica para seguir directrices con la intencionalidad de detectar, } \\
\text { seleccionar y promover las BBPPEE en una demarcación específica usualmente } \\
\text { correspondiente a los propios organismos que establecen los programas. } \\
\text { Se materializan en forma pasiva o activa. Suelen ser periódicos, siendo común } \\
\text { que la culminación corresponda a un evento donde se hace un } \\
\text { reconocimiento público a los autores y ejecutores de las BBPPEE. }\end{array}$ & $\begin{array}{c}\text { Activo } \\
\text { o pasivo }\end{array}$ & $2,9,32$ \\
\hline $\begin{array}{c}\text { Bancos } \\
\text { de BBPPEE }\end{array}$ & $\begin{array}{l}\text { Son repositorios donde se cataloga y depositan las BBPPEE, todas las } \\
\text { estrategias mencionadas anteriormente deben considerar un destino para almacenar } \\
\text { la información que recaban, desde esta perspectiva, los bancos no son un mecanismo } \\
\text { de recopilación, puesto que constituyen el destino y no el medio para hacerlo, } \\
\text { sin embargo, algunos bancos no están supeditados a otras estrategias y están } \\
\text { abiertos para recibir BBPPEE en cualquier momento, en este escenario, } \\
\text { quienes comparten BBPPEE no buscan reconocimiento, sino la validación } \\
\text { de su experiencia por los dictaminadores del banco. }\end{array}$ & Pasivo & $21,22,23$ \\
\hline
\end{tabular}


se mencionan o se han utilizado en la revisión realizada. Cada uno de estos formatos posee características particulares que condicionan la documentación de las BBPPEE.

El principal propósito del artículo es la presentación de los resultados de aplicación de la BPE a una comunidad científica. El formato IMRyD propio de este tipo de publicación aporta rigor metodológico que beneficia la fundamentación y el detalle de la explicación de las BBPPEE, sin embargo, la articulación y el contenido que desarrollan varía en función del interés del autor -principalmente dirigido a la divulgación científica-, por lo que el discurso escrito no necesariamente está orientado a promover el intercambio de la BPE.

El libro es otro de los soportes en que es frecuente encontrar compendios de BBPPEE. Las BBPPEE que se presentan en los libros no necesariamente pasaron por un proceso riguroso para acreditarlas, su selección y la información que exhiben ha sido determinada por el autor o el equipo editorial de la obra; por lo anterior, el alcance del propósito de las BBPPEE documentadas en este formato es la difusión de experiencias, estrategias o métodos que a criterio de los autores corresponden a las BBPPEE que se publican. Cinco obras del corpus de la revisión corresponden a libros que compendian BBPPEE.

Las fichas documentales son otro tipo de formato para recabar información de las BBPPEE. Los datos solicitados varían en función de los criterios, atributos y objetivos establecidos por el programa o estrategia de detección en que se empleen. La información recabada permite que sea evaluada para distinguirla como BPE y eventualmente promoverla para su replicación. Las fichas documentales se almacenan en repositorios o bancos de BBPPEE donde pueden ser consultadas por terceros.

Tabla 7. Información que forma parte de la documentación de las BBPPEE.

\begin{tabular}{ccc} 
Dato & Descripción & Frecuencia \\
\hline Título & Nombre que se le da a la práctica y con el cual será reconocida & 7 \\
\hline Autores & Personas involucradas en el diseño y ejecución de la práctica & 7 \\
\hline Descripción & Explicación de la práctica preponderantemente para fines de presentación & 7 \\
\hline Beneficiarios & Personas o grupos que se benefician con la práctica, usualmente estudiantes & 7 \\
\hline Problemática & Descripción de las aportaciones de la práctica para resolver una problemática \\
preponderantemente de aprendizaje & 7 \\
\hline Resultados & Descripción de los resultados que se obtuvieron o se esperan obtener al implementar la práctica las características del escenario educativo & 7 \\
\hline Procedimiento & en donde aconteció o se desarrolló la práctica & 7 \\
y alcance & Detalle de pasos o etapas que conlleva la implementación de la práctica, & 6 \\
\hline Fundamentación & Teorías o conceptos pedagógicos, o bien justificación sobre & 6 \\
\hline
\end{tabular}


En esta revisión se analizaron siete fichas (FONDEP, 2019; Espol, 2019; CoDAJIC, 2019; Universitat de València, 2017; MEE, 2017; OIT, 2015; AAEE, 2012) que se presentan o refieren en los textos analizados. En la tabla 7 se presentan los datos que con mayor frecuencia se solicitan para documentar a las BBPPEE.

\section{Aportación de las tecnologías digitales a las buenas prácticas educativas}

Por tecnologías digitales nos referimos a aquellos artefactos, dispositivos o servicios cuya operación esté sustentada en las tecnologías de información y comunicación (TIC) y que en el contexto educativo se aplican mediante estrategias pedagógicas para favorecer el acceso al conocimiento y aprendizaje de los estudiantes. En torno a las tecnologías digitales profesores y estudiantes encuentran nuevas formas de generar y compartir conocimientos a través de herramientas y métodos que no están limitados por barreras de tiempo y espacio. Lo anterior ha dado paso a la aparición de nuevos términos o conceptos complementarios que caracterizan el propósito de la aplicación de las TIC en el contexto educativo y que de fondo aspiran a contrarrestar la visión instrumental que en ocasiones se percibe.

Bajo este planteamiento hay consenso en la literatura en que las tecnologías digitales juegan un papel relevante para lograr la innovación que caracteriza a las BBPPEE. Si bien es cierto que el simple hecho de integrarlas no representa ni les otorga la cualificación de innovadoras, las tecnologías digitales posibilitan la incursión de nuevas formas de aplicar las pedagogías a través del diseño de escenarios educati-

Tabla 8. Principales aportaciones de las tecnologías digitales a las BBPPEE.

\begin{tabular}{|c|c|c|}
\hline Aportación & Descripción & $\begin{array}{l}\text { Referentes } \\
\text { (ver autores } \\
\text { en tabla 2) }\end{array}$ \\
\hline $\begin{array}{l}\text { Mejora del rendimiento } \\
\text { académico y motivacional } \\
\text { de los estudiantes }\end{array}$ & $\begin{array}{l}\text { Bajo esta perspectiva las BBPPEE se sustentan en las tecnologías digitales para } \\
\text { generar escenarios o ambientes de aprendizaje que envuelven al estudiante en una } \\
\text { experiencia digital que activa sus sentidos y les permite interactuar e intercambiar } \\
\text { conocimientos con resultados positivos en su rendimiento y motivación }\end{array}$ & $\begin{array}{c}4,5,9 \\
11,18,32\end{array}$ \\
\hline $\begin{array}{c}\text { Desarrollo de la educación } \\
\text { en línea o virtual }\end{array}$ & $\begin{array}{l}\text { Las BBPPEE se intercambian para incentivar el desarrollo de la } \\
\text { educación en línea o virtual, docentes intercambian experiencias y } \\
\text { dan consejos para mejorar los procesos de enseñanza, evaluación y gestión }\end{array}$ & $\begin{array}{c}14,17 \\
20,24,26\end{array}$ \\
\hline $\begin{array}{l}\text { Innovación educativa } \\
\text { y cambios en los } \\
\text { modelos de enseñanza } \\
\quad \text { y aprendizaje }\end{array}$ & $\begin{array}{l}\text { Bajo este enfoque las tecnologías digitales contribuyen a que docentes } \\
\text { y estudiantes exploren nuevos métodos, estrategias y modelos que se } \\
\text { distancian de los métodos tradicionales en el uso del tiempo y el espacio } \\
\text { incentivando el pensamiento creativo y la resolución de problemáticas reales }\end{array}$ & $\begin{array}{l}2,3,9,12 \\
15,16,19 \\
18,24,32\end{array}$ \\
\hline $\begin{array}{l}\text { Transformación } \\
\text { del rol del docente }\end{array}$ & $\begin{array}{l}\text { Las tecnologías digitales contribuyen a que el docente migre su labor } \\
\text { hacia una enseñanza centrada en el aprendizaje convirtiéndose en } \\
\text { curador de contenidos, tutor y diseñador de experiencias de aprendizaje }\end{array}$ & $6,13,15,20,26$ \\
\hline
\end{tabular}


vos más flexibles y centrados en el estudiante. Así mismo el mundo digital en el que vivimos trasciende todas las actividades humanas, por lo que los procesos educativos suceden también en ambientes digitales, y por ello diversos autores presentan como BBPPEE aquellas experiencias que posibilitan la incursión en tales ambientes o escenarios mediados por la tecnología, como la educación en línea. Como parte de esta revisión se ha indagado en los textos analizados sobre las principales aportaciones que atribuyen a las tecnologías digitales para la materialización de las BBPPEE (tabla 8).

\section{Límites en torno al concepto de BBPPEE}

El análisis de la literatura permite identificar diversos debates y corrientes que ubican a su origen, significado y alcances en un escenario polisémico que obliga a reconocer que, a pesar del interés que se percibe en el discurso de los actores e instituciones del contexto educativo, existen contradicciones e inconsistencias que ubican su conceptualización en un escenario amplio e inconcluso. En principio, los enfoques para establecer la cualificación de una práctica como buena permiten identificar dos corrientes: (1) aquella que considera que la buena intencionalidad de la práctica la define como tal y (2) aquella que considera que la acreditación de ciertos criterios -como ejemplo, la efectividad- es lo que la define como buena; lo que representa dos posturas en contrasentido: bajo un enfoque, la cualificación se otorga desde la ideación de la práctica y el criterio del autor; desde el otro, la cualificación se logra hasta el final de un proceso, una vez que los resultados obtenidos de la replicación de terceros permite acreditar el cumplimiento de los criterios que caracterizan a las BBPPEE.

Respecto a la incursión del concepto en el campo educativo, no se puede determinar con exactitud en qué momento sucede. Diversos autores reconocen que su origen pertenece a otras esferas vinculadas a la cultura de calidad y procesos de gestión. La atractiva idea de encontrar casos de éxito para replicarlos buscando extender los beneficios de las prácticas en nuevos contextos ha permeado con mayor incidencia en el terreno educativo desde la primera década del siglo XXI. Lo anterior se puede constatar en los diversos marcos de conceptualización que han sido desarrollados por organismos como la OIT (2015), la UNESCO (citado por Caldeiro-Pedreira, Yot-Domínguez y Castro-Zubizarreta, 2018), el FONDEP (2019) en Perú o el extinto INEE (2016) en México, así mismo diversos académicos se han esmerado por construir un andamiaje que sustente el diseño de estrategias para movilizar el intercambio de las BBPPEE entre los actores u organizaciones que pertenecen a las diversas comunidades del sector educativo.

A pesar de los esfuerzos de las organizaciones o los académicos por establecer criterios en torno a la conceptualización y sistematización de las BBPPEE-como se ha mencionado antes-, existen al menos cuatro acepciones que describen las posibles 
interpretaciones que se pueden asociar con su significado, que puede referir desde una simple recomendación hasta un modelo de proceso o actuación. Por ello, si se desea incursionar en el desarrollo de estrategias para movilizar el intercambio de las BBPPEE es fundamental partir de una conceptualización situada y establecer alcances alineados a los objetivos particulares del contexto en donde se deseen implementar.

\section{Conclusiones}

A pesar de que los resultados del análisis de los textos revisados no permiten establecer con contundencia los diversos métodos que se utilizan para la detección y documentación de las BBPPEE, es posible deducir de la revisión que el proceso se realiza en dos etapas, en la primera se establecen criterios de selección en forma de marcos procedimentales, políticas y lineamientos que establecen las directrices para la siguiente etapa, que corresponde a la recopilación. La recopilación de BBPPEE puede ser pasiva cuando se emite una convocatoria para un premio, concurso o evento académico con la intención de atraerlas para evaluarlas y reconocerlas.

La detección es activa cuando, en lugar de esperar a que lleguen las BBPPEE, se establecen estructuras y se destinan recursos para indagar en la comunidad e identificar las experiencias que por sus características puedan ser reconocidas como buenas. La propuesta de considerar a los métodos de identificación como pasivos o activos es una de las contribuciones que se hacen en este trabajo, deducidas a partir de la revisión bibliográfica.

La detección está estrechamente relacionada con el proceso de documentación de las BBPPEE, cada estrategia establece las directrices para elaborar la documentación que se espera recibir; en el caso de los eventos académicos la estructura está dada por los estándares de producción científica y las directrices que establece el comité que organiza el evento o publicación académica. En lo general este tipo de estrategias no tiene como propósito promover la replicación de las BBPPEE sino presentar a una comunidad científica los resultados de su implementación, por lo anterior, la descripción de las prácticas no necesariamente evidencia el cumplimiento de los atributos que caracterizan a las BBPPEE. Pese a ello, es la fuente más abundante para encontrarlas, puesto que estructuras como los bancos de BBPPEE son escasas en el Internet.

Los bancos o repositorios son el destino que diversas estrategias establecen para almacenar la documentación asociada a una BPE, ya sea en espacios físicos o virtuales, representan una especie de biblioteca que puede o no estar vinculada con otras estrategias de identificación como los observatorios o los programas de detección. La información que se recaba en un banco de BBPPEE está asociada a los atributos previamente referidos. En lo general los bancos recopilan evidencia que acredita la efectividad, sostenibilidad, innovación y pertinencia de las prácticas. 
Con relación a la presencia y reconocimiento formal de los bancos de BBPPEE en Internet, es necesario decir que son escasos, y los que existen contienen una cantidad reducida de BBPPEE, lo que abre la posibilidad hacia trabajo a futuro de investigar los motivos por lo que esto ocurre, quizá por la dificultad de construir y asimilar prácticas que cumplan con todos los criterios que permitan encuadrarlas bajo tal concepto, siendo además un proceso que toma tiempo para madurar, requiriendo de una comunidad comprometida en sostenerlas. En contrasentido, existe en Internet una cantidad abundante de espacios virtuales que, aunque no se promueven formalmente como repositorios o bancos de BBPPEE, publican contenidos, recursos didácticos y recomendaciones dirigidas hacia los docentes bajo la bandera de buenas prácticas.

En lo general, se puede establecer que la revisión descriptiva que se presenta aporta información relevante que contribuye a la conceptualización de las BBPPEE en el contexto de la educación superior, de sus principales atributos y estrategias para su detección y documentación. Las BBPPEE no están supeditadas a la integración de las tecnologías digitales, sin embargo existe una clara valoración de estas para aportar innovación a las prácticas, incidir en la motivación de los estudiantes, transitar hacia nuevas modalidades educativas y promover la transformación del rol del docente y del escenario educativo.

En torno a la evolución de las BBPPEE en los últimos diez años, es evidente que el concepto se ha arraigado en la esfera educativa, por ello existen innumerables publicaciones y sitios en Internet donde se promueven bajo alguna de las tipologías deducidas y presentadas en este trabajo. Así mismo la comunidad científica continúa desarrollando investigación sobre la evolución del concepto, en parte por la necesidad de establecer un orden que permita detectarlas en el escenario educativo y transferirlas con criterios homologados, así mismo para otorgar reconocimiento a todos los esfuerzos y experiencias en que se ha logrado acreditar los buenos resultados de su implementación. Como trabajo a futuro se pretende indagar sobre los diferentes métodos para evaluar y difundir las BBPPEE en el contexto de la educación superior.

\section{REFERENCIAS}

AAEE [Agencia Andaluza de Evaluación Educativa] (2012). Guía de buenas prácticas docentes. Junta de Andalucía: Sevilla. Recuperado de: http://goo.gl/ LNyvTW.

Acuña S., M., Gil R., M. E., y Sandoval P., M. (2016). Buenas prácticas para la selección de recursos educativos abiertos: experiencias del MOOC innovación educativa con REA. Actualidades Investigativas en Educa- ción, 16(2). Recuperado de: https://doi.org/10.15517/ aie.v16i2.23559.

Antisdel, N. (2016). In search of definitive best practices for online bigher education [Tesis]. University of the Cumberlands. Recuperado de: https://doi.org/10.13140/ RG.2.2.15234.89284.

Blanco, Á. F., Lacleta, M. L. S., y García-Peñalvo, F. J. (2019). Método para diseñar buenas prácticas de innovación 
educativa docente: percepción del profesorado. V Congreso Internacional sobre Aprendizaje, Innovación y Competitividad (CINAIC 2019, oct.). Recuperado de: https://doi.org/10.26754/CINAIC.2019.0127.

Borges, Á., Rodríguez-Naveiras, E., Díaz, M., Domínguez, M., González de la Fé, T., Dorta, R. L., e Isla, R. (2016). The observational instrument of best practices: An observational instrument to measure best practice behaviors in university teachers. International Journal of Social Science Studies, 4(10). Recuperado de: https://doi.org/10.11114/ijsss.v4i10.1868.

Caldeiro-Pedreira, M.-C., Yot-Domínguez, C., y CastroZubizarreta, A. (2018). Detección de buenas prácticas docentes de uso de dispositivos móviles en primaria a través del análisis documental. Revista Prisma Social, (20), 58-75. Recuperado de: http:/ / revistaprismasocial.es/article/view/2293/2475.

Cámara A., S. (2012). Concepto y elementos característicos de las "mejores prácticas" aplicados a las Defensorías del Pueblo en Iberoamérica. En S. Cámara y Luna, E., Mejores prácticas del Ombudsman en Iberoamérica. Madrid, España: Dykinson.

Claro, M. (2010). La incorporación de tecnologías digitales en educación. Modelos de identificación de buenas prácticas. Colección Documentos de Proyectos, 3(2), 1-30. Recuperado de: https://dds.cepal.org/redesoc/ publication?id=1104.

Codajic [Confederación de Adolescencia y Juventud de Iberoamérica, Italia y el Caribe] (2019). Formulario de buenas prácticas 2019. Compartiendo miradas 2019. Recuperado de: http://www.codajic.org/sites/www. codajic.org/files/Formulario $\% 20$ Compartiendo $\% 20$ miradas\%20\%202019.pdf.

Contreras, A. M., y Ochoa Jiménez, R. J. (2010). Manual de redacción cientifica. Escribir artículos cientificos es fácil, después de ser difícil. Una guía práctica. Guadalajara: Ediciones de la Noche.

Cué, M., Díaz, G., Díaz, A., y Valdés, M. (2008). El artículo de revisión. Revista Cubana de Salud Pública, 34(4). Recuperado de: http:/ /scielo.sld.cu/scielo.php?script=sci_ arttext\&pid=S0864-34662008000400011.

Durán Rodríguez, R., y Estay-Niculcar, C. A. (2016). Las buenas prácticas docentes en la educación virtual universitaria. REDU. Revista de Docencia Universitaria,
14(2), 159. Recuperado de: https://doi.org/10.4995/ redu.2016.5905.

Durán, R., Estay-Niculcar, C., y Álvarez, H. (2015). Adopción de buenas prácticas en la educación virtual en la educación superior. Aula Abierta, 43(2), 77-86. Recuperado de: https://doi.org/10.1016/j. aula.2015.01.001.

Espol [Escuela Superior Politécnica del Litoral] (2019). Formulario de presentación de buenas prácticas. TELESCOPI Observatorio de Buenas Prácticas de Dirección Estratégica Universitaria. Recuperado de: http://telescopi.espol.edu.ec/wp-content/uploads/2016/06/ Formulario-de-Presentaci $\%$ C3\%B3n-de-Buenas$\mathrm{Pr} \% \mathrm{C} 3 \%$ A1cticas-2.pdf.

Fernández A., M. (2016). Modelo educativo emergente en las buenas prácticas TIC. Revista Fuentes, 18(18), 3347. Recuperado de: https://revistascientificas.us.es/ index.php/fuentes/article/view/2813.

Flores Hernández, A., Díaz Barriga Arceo, F., y Rigo Lemini, M. A. (2016). Construcción de buenas prácticas educativas mediadas por tecnología. Puebla, México: Benemérita Universidad Autónoma de Puebla.

FONDEP [Fondo Nacional de Desarrollo de la Educación Peruana] (2014). Marco de la innovación y las buenas prácticas educativas en el Perú. Lima, Perú: Derrama Magisterial.

FONDEP [Fondo Nacional de Desarrollo de la Educación Peruana] (2019). Bases para el concurso de Mentoría de BBPP 2019. Recuperado de: https://www.fondep. gob.pe/concurso-mentoria-buenas-practicas/.

Gañán G., B., y Rozo M., E. (2015). Superficies de emergencia del concepto buenas prácticas educativas [Tesis de maestría]. Universidad Pedagógica Nacional, Bogotá. Recuperado de: http://repository.pedagogica.edu. co/bitstream/handle/20.500.12209/637/TO-18131. pdf? sequence $=1$ \&isAllowed $=\mathrm{y}$.

González, T. (2007). El concepto de "buenas practicas": origen y desarrollo. Comunicación y Pedagogía, (222), 32-47. Recuperado de: http://www.centrocp.com/ comunicacionypedagogia/comunicacion-y-pedagogia-222.pdf.

Gradaille P., R., y Caballo V., M. (2016). Las buenas prácticas como recurso para la acción comunitaria: criterios de identificación y búsqueda. Contextos Edu- 
cativos. Revista de Educación, (19), 75-88. Recuperado de: https://doi.org/10.18172/con.2773.

Guirao-Goris, J. A., Olmedo, A., y Ferrer, E. (2008). El artículo de revisión. Revista Iberoamérica de Enfermería Comunitaria, (1), 1-6. Recuperado de: https://goo.gl/ Ryxgvg.

Guzmán, J. C. (2018). Best teaching practices of university professors. Revista Iberoamericana sobre Calidad, Eficacia y Cambio en Educación, 16(2), 133-149. Recuperado de: https://doi.org/10.15366/reice2018.16.2.008.

Henríquez Fierro, E. y Zepeda González, M. I. (2004). Elaboración de un artículo científico de investigación. Ciencia y Enfermería, 10(1), 17-21. Recuperado de: https://scielo.conicyt.cl/scielo.php?script=sci_ abstract\&pid $=$ S0717-95532004000100003\&lng $=$ es \&nrm=iso.

Hernández, M., Borges, R., Valadez, S., y Zambrano, G. (2015). Valoración de buenas prácticas docentes a través de observación sistemática. Universitas Psychologica, 14(3), 913-922. Recuperado de: https://doi. org/10.11144/Javeriana.upsy14-3.vbpd.

INEE [Instituto Nacional para la Evaluación de la Educación en México] (2016). Detección de buenas prácticas locales de evaluación y uso de los resultados para la mejora [Documento técnico]. Recuperado de: https:/ / www.inee.edu.mx/directrices-para-mejorar/pnee/ documentos-de-apoyo-pnee/.

Jeri R., D. (2008). Buenas prácticas en el ámbito educativo y su orientación a la gestión del conocimiento. Educación, 17(33), 3.

Lévy, P. (2004). Inteligencia colectiva por una antropología del ciberespacio (trad. A. F. Martínez). Washington: Infomed. Recuperado de http://inteligenciacolectiva.bvsalud.org/public/documents/pdf/es/ inteligenciaColectiva.pdf.

Keppell, M., Suddaby, G., y Hard, N. (2015). Assuring best practice in technology-enhanced learning environments. Research in Learning Technology, 23(1). Recuperado de: https://doi.org/10.3402/rlt.v23.25728.

MEE [Ministerio de Educación de Ecuador] (2017). Buenas prácticas educativas exitosas y/o innovadoras. Recuperado de: https://www.educarecuador.gob.ec/ anexos/Correo_Docentes_para_identificar_Buenas_Practicas_Educativas.pdf.
OEI-Ibertic [Equipo IberTic de la Organización de Estados Iberoaméricanos para la Educación la Ciencia y la Cultura] (2016). Manual para la evaluación de proyectos de inclusión de TIC en educación. Recuperado de: https:/ / oei.org.ar/ibertic/evaluacion/pdfs/ibertic_manual. pdf.

OIT [Organización Internacional del Trabajo] (2015). Guia para el intercambio de buenas prácticas y lecciones aprendidas para combatir el trabajo infantil y promover el trabajo decente. Recuperado de: http://white.lim.ilo.org/ipec/ documentos/gui_a_intercambio_de_buenas_pra_cticas_cambios.pdf.

Otto, S., Evins, M. A., Boyer-Pennington, M., y Brinthaupt, T. M. (2015). Learning communities in higher education: Best practices. Journal of Student Success and Retention, 2(1), 1-20. Recuperado de: http:/ / www.jossr.org/wp-content/uploads/2015/10/ Learning-Communities-in-Higher-Education-JoSSRsubmission-revised-10-26-2015.pdf.

Pacansky-Brock, M. (2017). Best practices for teaching with emerging technologies. Nueva York: Routledge.

Padilla P., S., Moreno, C. I., y Hernández C., R. (2015). Barreras para la integración de buenas prácticas con TIC. Estudio de caso. Innoeduca. International Journal of Technology and Educational Innovation, 1(2), 80. Recuperado de: https://doi.org/10.20548/innoeduca.2015. v1i2.1044.

Pérez A., S., y Akombo, D. (2019). Research, technology and bestpractices in education. Eindhoven: Adaya Press. Recuperado de: http://www.adayapress.com/wp-content/ uploads/2019/07/RTbestpractices.pdf.

Power, J., y Kannara, V. (2016). Best-practice model for technology enhanced learning in the creative arts. Research in Learning Technology, 24(302331). Recuperado de: https://doi.org/10.3402/rlt.v24.30231.

Ruiz-Bolívar, C., y Dávila, A. A. (2016). Propuesta de buenas prácticas de educación virtual en el contexto universitario. Revista de Educación a Distancia (RED), 49(12). Recuperado de: https://doi.org/10.6018/ $\mathrm{red} / 49 / 12$.

Singh, R., y Saroha, D. (2019). Role of innovations in teaching-learning and best practices in transforming higher education institutions. International Journal of Scientific Research and Review, 7(4). pp. 830-836. 
Sorter, H. (2019). Bestpractices of learning analytics implementations in higher education [Trabajo de grado]. University of Oregon, Eugene, OR, EE.UU.

Tobón, S., Martínez, J., Valdez R., E., y Quiriz, T. (2018). Prácticas pedagógicas: Análisis mediante la cartografía conceptual. Espacios, 39(53), 16. Recuperado de: http://www.revistaespacios.com/cited2017/cited2017-31.pdf.

Universitat de València (2017). Premis de l'Observatori de Bones pràctiques Excellentia Ex Cathedra 2017-2018.
Recuperado de: https://www.uv.es/uvweb/catedresinstitucionals/ca/excellentia-ex-cathedra/repositoribones-practiques/repositori-bones-practiques/ divulgacio-difusio-1286047016244.html.

Wilczynski, V. y Cook, M. (2017). Identifying and sharing best practices in international higher education makerspaces. 2017 ASEE International Forum, Columbus, OH, EE.UU. Recuperado de: https://peer.asee.org/identifyingand-sharing-best-practices-in-international-highereducation-makerspaces.pdf.

Cómo citar este artículo:

Mondragón Beltrán, E. Á. A., y Moreno Reyes, H. (2020). Revisión del concepto de buenas prácticas educativas que integran tecnologías digitales en el nivel superior: enfoques para su detección y documentación. IE Revista de Investigación Educativa de la REDIECH, 11, e916. doi: https://doi.org/10.33010/ie_rie_rediech.v11i0.916. 